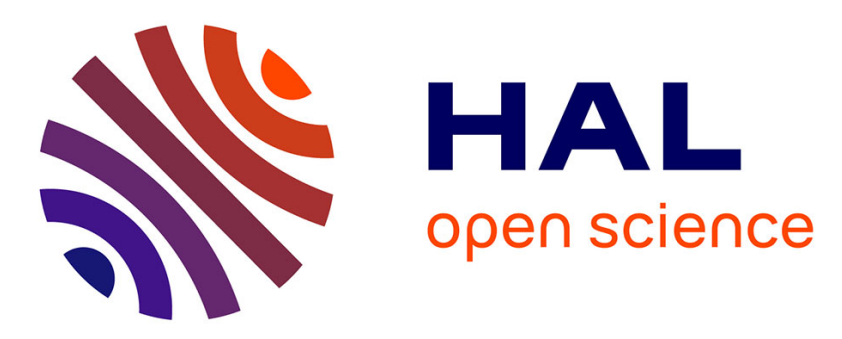

\title{
Piston Motion Performance Analysis of a 3DOF Electrothermal MEMS Scanner for Medical Applications.
}

\author{
Alberto Espinosa, Kanty Rabenorosoa, Cédric Clevy, Bilal Komati, Philippe \\ Lutz, X. Zhang, R. Samuelson, H. Xie
}

\section{To cite this version:}

Alberto Espinosa, Kanty Rabenorosoa, Cédric Clevy, Bilal Komati, Philippe Lutz, et al.. Piston Motion Performance Analysis of a 3DOF Electrothermal MEMS Scanner for Medical Applications.. International Journal of Optomechatronics, 2014, 8, pp.179-194. hal-01324538

\section{HAL Id: hal-01324538 \\ https://hal.science/hal-01324538}

Submitted on 7 Jul 2016

HAL is a multi-disciplinary open access archive for the deposit and dissemination of scientific research documents, whether they are published or not. The documents may come from teaching and research institutions in France or abroad, or from public or private research centers.
L'archive ouverte pluridisciplinaire HAL, est destinée au dépôt et à la diffusion de documents scientifiques de niveau recherche, publiés ou non, émanant des établissements d'enseignement et de recherche français ou étrangers, des laboratoires publics ou privés. 


\title{
Piston Motion Performance Analysis of a 3DOF Electrothermal MEMS Scanner for Medical Applications
}

\author{
A. Espinosa, K. Rabenorosoa, C. Clévy, B. Komati and P. Lutz \\ FEMTO-ST Institute, UMR CNRS/ENSMM/UFC/UTBM, \\ 24 rue Alain Savary, 25000 Besancon, France \\ Email: aberto.espinosa, rkanty, cclevy, bilal.komati, plutz@femto-st.fr \\ X. Zhang, S. R. Samuelson and H. Xie \\ Interdisciplinary Microsystems Group, University of Florida, Gainesville, USA \\ Email: xzhang292, cap315, hkx@ufl.edu
}

April 21, 2014

\begin{abstract}
MEMS scanners are useful for medical applications as optical coherence tomography, and laser microsurgery. Although widespread design of MEMS scanners have been presented, their behaviour is not well known and thus their motions are not easily and efficiently controlled. This lack induces several difficulties (limited resolution, accuracy, cycle time, etc.) and to tackle this problem, the paper presents the modeling of an ISC electrothermally actuated MEMS mirror and the experimental characterization for the piston motion. Modeling and characterization are important to implement the control. A multiphysic model is proposed and an experimental validation is performed with a good correspondence for a voltage range from $0 \mathrm{~V}$ to $3.5 \mathrm{~V}$ with a maximum displacement up to $200 \mu \mathrm{m}$ and with a relative tilting difference of $0.1^{\circ}$. The paper also presents a simple and efficient experimental setup to measure a displacement in dynamic and static mode or a mirror plane tilting in static mode.
\end{abstract}




\section{Introduction}

The increasing use of MEMS (Micro Electro-Mechanical-Systems) and MOE-MS (MicroOpto-Electro-Mechanical-Systems) is observed in many fields such as medical applications as mentioned in [1]. There are some applications based on optical microsystems which are under investigation as microspectrometers in [2], and in [3], confocal microscope for sample analysis in [4], Optical Coherence Tomography (OCT) for in-vivo cancer detection in [5], [6], [7], and [8], and laser microsurgery in [9]. It is observed that most optical microsystems are based on MEMS scanners. The design and fabrication of MEMS scanners are widely investigated by considering the Degrees of Freedom (DoFs) number, kinematics, and microactuator integration. Generally, we can classify MEMS scanners into two main categories according to the type of motion generated:

- In-plane displacement presented in [3], [2], [10], [11], [12] for 1 DoF, and [13], [4] for 2 $\operatorname{DoF}(\mathrm{X}-\mathrm{Y})$.

- Out-of-plane displacement which can be 2 DoF (Tip-Tilt) presented in [14, 15, 16, 17], and 3 DoF (Tip-Tilt-Piston Motion) presented in [18], [19], [5].

In-plane motion is usually used for confocal microscopes and spectrometers where the displacement is observed in the substrate plane. Out-of-plane motion is required to deflect a laser beam in order to scan a sample surface like laser microsurgeries and OCT. There are several characteristics (response time, hysteresis, angle variations, mirror flatness, etc.) which are important for scanner performances. Consequently, they will define the working performance of each optical microsystems. Two important working modes are often considered: static and dynamic. In addition, there are some parameters to be characterized as linearity, response, resolution, and cross-axis coupling. Indeed, these parameters directly determine the specifications of the optical systems, eg. the image frame rate, distortion for OCT, and precision of microsurgery. It is observed that the characterization of MEMS

performances is very difficult according to [20] due to the lack of sensors and procedures. At 
the microscale, the physical properties of material and the obtained behaviour from micromachining are difficult to characterize. Few works can be found about the procedure in the literature such as [21], and [22]. In addition, the results obtained through the characterization can be used to check if the micromachining provides the expected behaviour, to obtain a feedback on the design (thus can be employed as inputs for re-engineering), and to work on the control aspects in order to improve the performances.

This paper is focused on scanner performance analysis of a 3DoF electrothermal MEMS for OCT. In section 2, the MEMS micromirror is presented through its design and fabrication processes. In section 3, a modeling of the MEMS micromirror is proposed based on kinematic and physical considerations. Afterwards, performance analysis of piston motion through experiments are presented in section 4. Finally, the section 5 concludes the paper.

\section{Presentation of the MEMS Micromirror}

MEMS micromirrors are important in the development of optical microsystems. Several kinds of actuator have been used in the literature with various kinematics, number of DoF, and design. A 3DoF electrothermal MEMS scanner design and fabrication is detailed in the following.

\subsection{Design}

The actuation mechanism used for the micromirror is the Inverted-Series-Connected (ISC) bimorph design comparable to [18], which can solve the rotation-axis shift problems during actuation. Also, large displacements can be achieved using the ISC bimorph design for actuation at relatively low drive voltage.

The concept of the ISC actuator is shown in Fig.1. For a basic bimorph, when the temperature is changed, it will bend because of the different Coefficients of Thermal Expansion(CTEs) of the two materials in the bimorph. There will be a tangential tilt generated at 


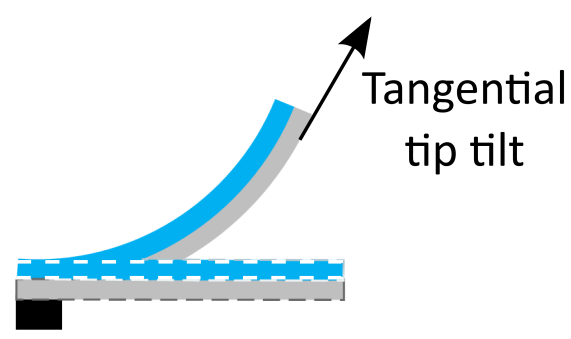

(a)

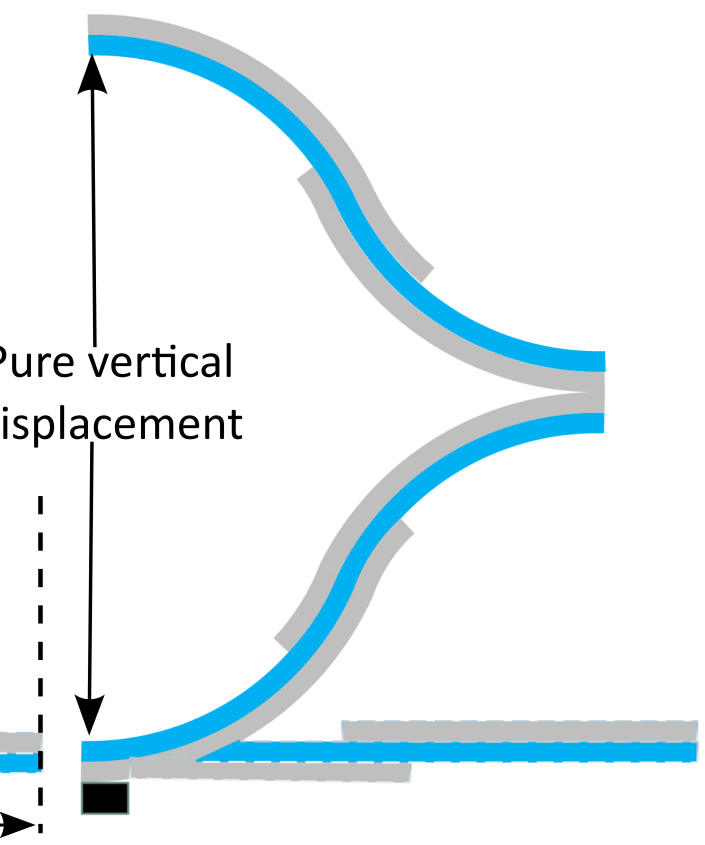

(b)

Lateral shift

(c)

Figure 1: The concept of ISC actuator with undeformed shape in solid and deformed in dashed. (a) Basic bimorph. (b) half ISC bimorph: zero tangential tip tilt but still lateral shift. (c) ISC bimorph of the micromirror: zero tip tilt and zero lateral shift.

the tip of the bimorph beam (Fig.1 (a)). If two basic bimorphs are inverted and connected in series, the tangential tilt can be canceled, but there still exists lateral shift (Fig.1 (b)). To achieve pure displacement in y-direction, two ISC bimorphs are connected to cancel the lateral shift, as shown in (Fig.1(c)). A properly-designed ISC actuator can achieve vertical displacement in y-axis with zero tip-tilt and zero lateral shift. In addition, the overlap part at the middle of each S-shaped bimorph is designed to improve the robustness of the actuator. The two layers in the bimorph are $\mathrm{Al}$ and $\mathrm{SiO}_{2}$ because of their large CTE difference and the ease for fabrication. An embedded $P t$ layer is used to provide uniform heat through the entire bimorph beam.

The schematic of the ISC micromirror design is shown in Fig.2 where four ISC actuators are connected to the central mirror plate. The connections between the ISC actuators and the mirror plate are pure $\mathrm{SiO}_{2}$ to isolate the heat generated in the actuators from the mirror plate. Also the thermal isolation can prevent the cross-talk through the mirror plate among 


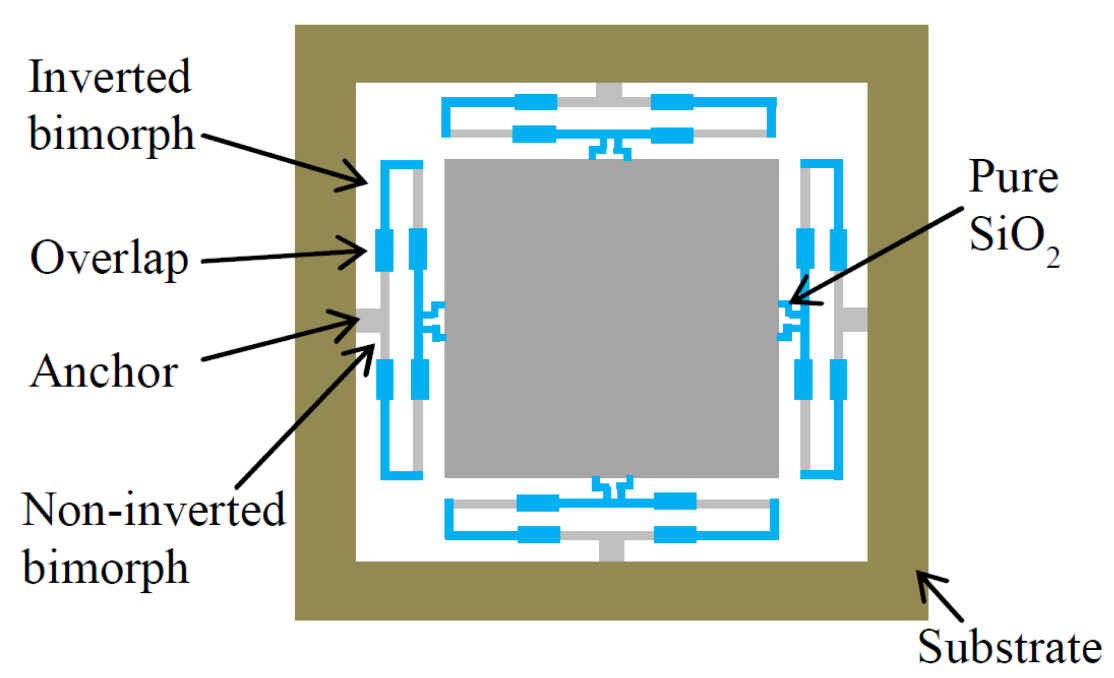

Figure 2: Top view of the ISC micro mirror design including 8 ISC bimorphs.

the actuators. The actuators can be controlled together or individually to achieve piston (pure motion along $\mathrm{Z}$ ) or tilt motion (rotation of the mirror plate around $\mathrm{X}$ and $\mathrm{Y}$ ). It has been proven in [18] that this design can generate large vertical displacements with small lateral shift or tilt.

\section{$2.2 \quad$ Fabrication}

The fabrication process of the micromirror is a combination of both thin-film and bulk processes. The mirror plate is a $1 \mu \mathrm{m}$-thick $A l$ layer coated on a $50 \mu \mathrm{m}$-thick layer of silicon to achieve good flatness. A SOI (Silicon On Insulator) wafer is chosen for better control of the fabrication process. The thin-film layers for bimorphs are deposited using PECVD (Plasma-Enhanced Chemical Vapor Deposition) or sputtering. Six photomasks are needed to form the entire structure.

The process flow is shown in Fig.3. The fabrication process starts with a SOI wafer. First, a $1 \mu \mathrm{m}$ layer of $\mathrm{SiO}_{2}$ is deposited using PECVD as the structure layer for the noninverted bimorph (Fig.3 (a)), followed by $\mathrm{SiO}_{2}$ RIE (Reactive Ion Etching) etching (Fig.3 (b)). Then a $0.2 \mu \mathrm{m}$ thick $P t$ is sputtered as the heater, followed by lift-off (Fig.3 (c)). After 


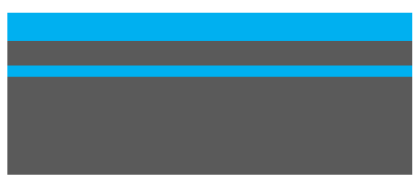

(a)

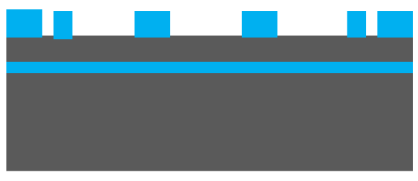

(b)

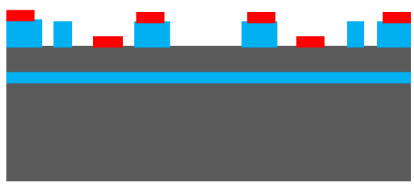

(c)

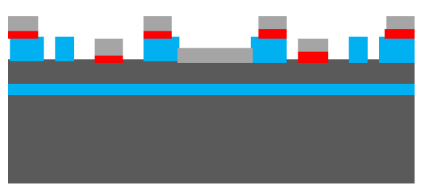

(d)

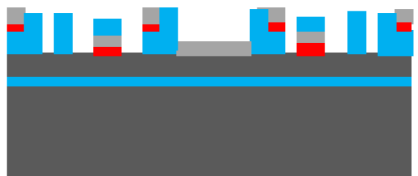

(e)

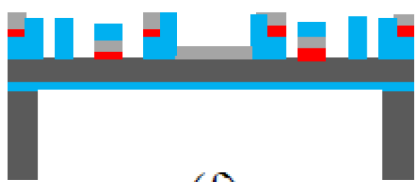

(f)

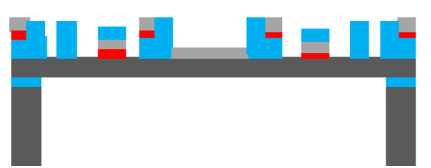

(g)

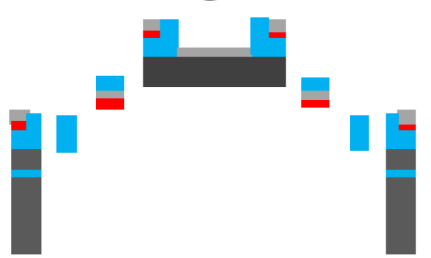

(h)

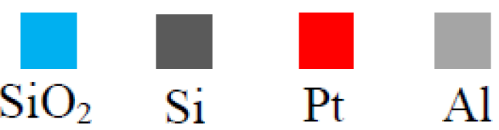

Figure 3: Flowchart of the ISC bimorph MEMS mirror : (a) $\mathrm{SiO}_{2}$ deposition, (b) RIE etching, (c) Pt deposition, (d) Insulation layer deposition followed by $\mathrm{Al}$ sputtering, (e) $\mathrm{SiO}_{2}$ deposition and etching, (f) DRIE etching of the handle layer, (g) buried oxyde etching and (h) Si etching to release the ISC bimorphs.

the formation of the heater, a thin $\mathrm{SiO}_{2}$ layer is deposited and followed by $\mathrm{SiO}_{2}$ RIE etching as the insulation layer between $P t$ and $A l$. The next step is $A l$ sputtering and lift-off to form the mirror plate and part of the structure for bimorphs (Fig.3 (d)). Then, the second $\mathrm{SiO}_{2}$ PECVD deposition and $\mathrm{SiO}_{2}$ RIE etching are performed to form the structural layer for inverted bimorphs (Fig.3 (e)). After the front side process, DRIE (Deep Reactive Ion Etching) is used to etch through the silicon handle layer of the SOI wafer to the buried oxide layer (Fig.3 (f)). Then the buried oxide is etched, resulting in a uniform silicon layer 
formed underneath the $\mathrm{Al}$ layer (Fig.3 (g)). The last step is isotropic $S i$ etching to release the bimorphs (Fig.3 (h)).

After the release step, the mirror plate will pop up because of the initial stress between $\mathrm{Al}$ and $\mathrm{SiO}_{2}$, as shown in Fig.4. The initial pop-up displacement is about $220 \mu \mathrm{m}$.
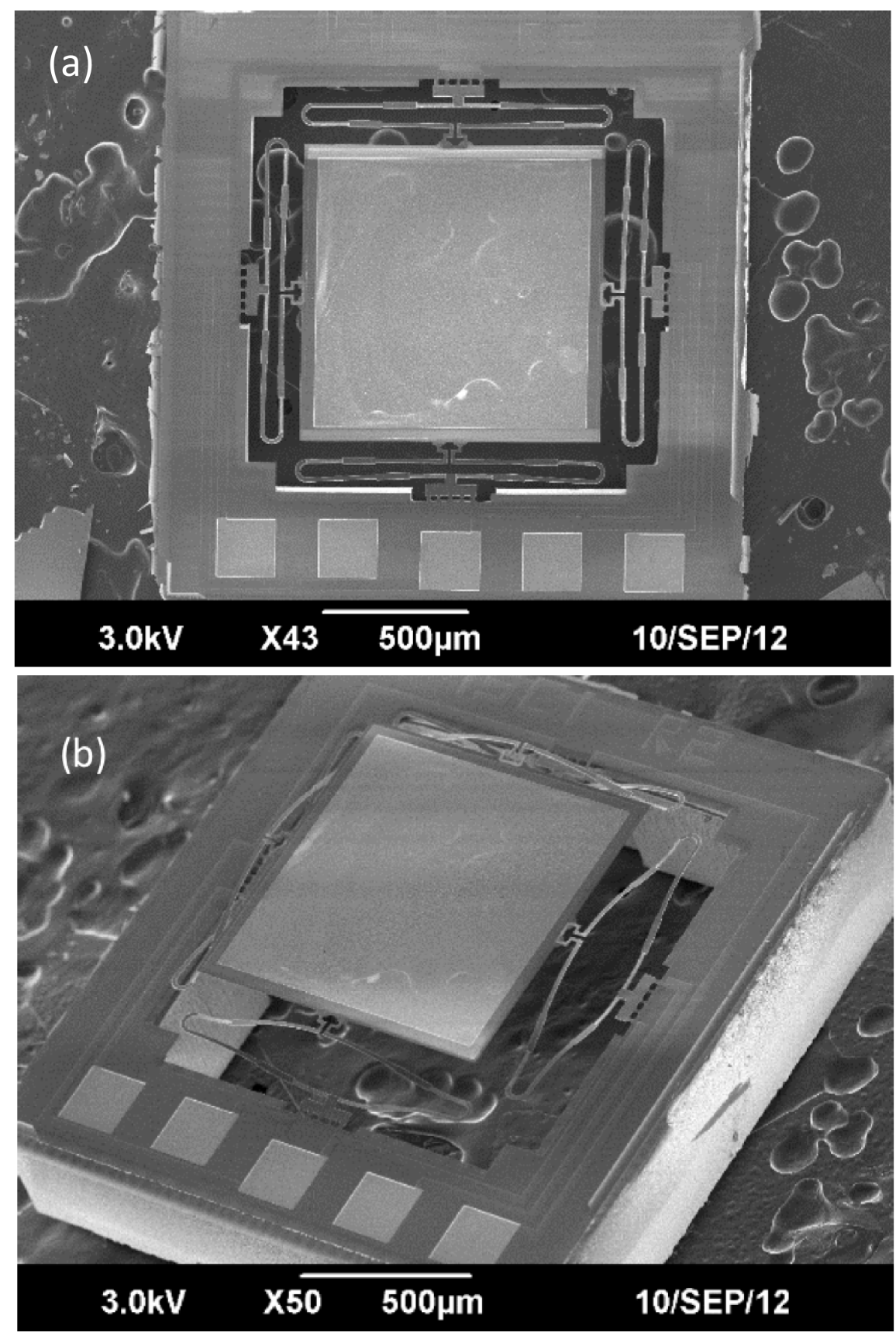

Figure 4: SEM pictures of the fabricated MEMS mirror: (a) top view, and (b) side view. 


\section{Piston motion modeling}

The modeling of the electrothermal actuated mirror is based on [23] and [24]. Fig.5 shows the sketch of the steps followed for modeling the ISC bimorphs. The model assumes that the deflection of the ISC $d_{I S C}$ bimorphs is equivalent to the displacement of the mirror platform $d_{\text {platform }}$ when the same voltage is applied to the four actuators (see equation (1)). The obtained motion is named piston motion. The displacement of the half ISC $d_{t}$ is considered to be the sum (equation (2)) of the deflections of one inverted bimorph $d_{I V}$, a straight multi-bimorph $d_{O L}$ or overlap and a non-inverted bimorph $d_{N I}$ as illustrated in (Fig.6) from [18].

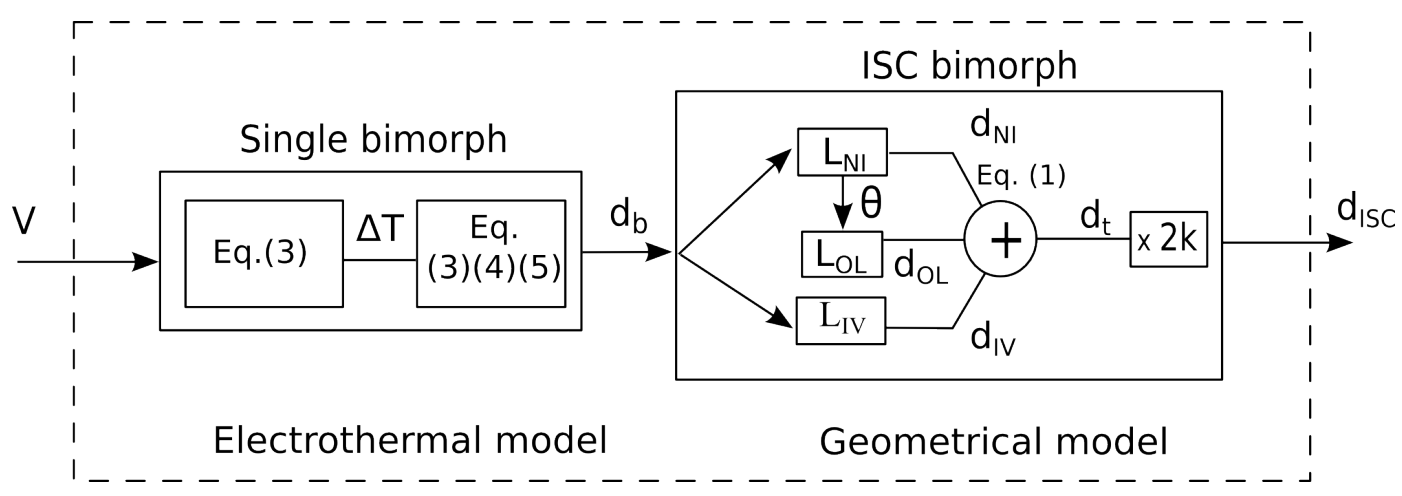

Figure 5: Followed steps to model ISC bimorph with $d_{b}$ the bimorph deflection, $V$ the applied voltage, $d_{I S C}$ the deflection of the ISC bimorph, $L_{N I}$ and $d_{N I}$ the length and deflection of non-inverted part, $L_{O L}$ and $d_{O L}$ the length and deflection of the overlap part, and $L_{I V}$ and $d_{I V}$ the length and deflection of the inverted part.

$$
\begin{gathered}
d_{\text {platform }}=d_{I S C}\left(V_{1}=V_{2}=V_{3}=V_{4}\right) \\
d_{t}=d_{N I}+d_{I V}+d_{O L}
\end{gathered}
$$

First, a single bimorph is modeled and the average temperature variation according to the voltage input is derived in equation (3). Note that in the following, some equations of the electrothermal model have been already reported in bibliography are given again to 
clarify the modeling. The increase of temperature on the bimorph is derived from [24] and it is available for other bimorphs.

$$
\Delta \bar{T}=\frac{V^{2}}{R_{0}(1+\xi \Delta \bar{T})} \bar{R}_{T}
$$

Where $R_{0}$ is the initial electrical resistance at ambient temperature, $V$ the applied voltage, $\xi$ is the thermal coefficient of resistance and $\bar{R}_{T}$ is the equivalent average effective thermal resistance. Due to the complexity of the calculation of $\bar{R}_{T}$ because of the ICS actuator geometry and the difficulties to quantify the thermal loses by mean of convection and conduction along the bimorph and the substrate and mirror isolation regions, this parameter has been identified using an experimental data. Solving equation (3) gives the average temperature change $\Delta \bar{T}$ due to a voltage input $V$ and derived in equation (4).

$$
\Delta \bar{T}=\frac{1}{2 \xi}\left(\sqrt{\frac{4 \xi R_{T}}{R_{0}} V^{2}+1}-1\right)
$$

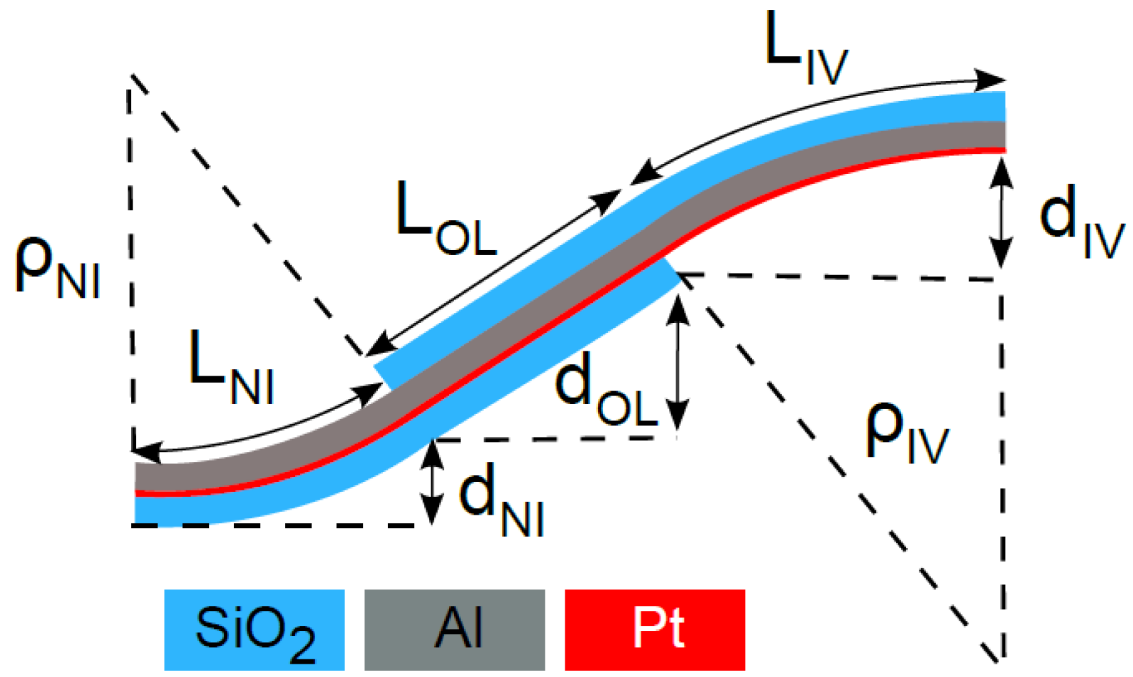

Figure 6: Description of half ISC bimorph with the three parts and three layers $\left(\mathrm{SiO}_{2}, \mathrm{Al}\right.$, and $P t)$.

The vertical tip deflection $d_{b}$ can be obtained by analyzing the Fig.6. Equation (5) gives 
the bimorph deflection as a function of the radius of curvature $\rho$ and angle $\theta$.

$$
\begin{gathered}
d_{b}=2 \rho \sin ^{2}\left(\frac{\theta}{2}\right) \\
\text { with } \frac{1}{\rho}=\frac{\beta_{b}}{t_{b}} \Delta \alpha \Delta T \\
\text { and } \theta=\frac{l_{b}}{\rho}=\frac{\beta_{b} l_{b}}{t_{b}} \Delta \alpha \Delta T
\end{gathered}
$$

The inverse of the bimorph radius of curvature, given in equation (6) is derived in [25] where $\beta_{b}$ is the curvature coefficient, $t_{b}$ is the thickness of the bimorph, $\Delta \alpha$ is the difference of the CTE of the two bimorph materials, and $\Delta T$ is the temperature variation. The curvature coefficient depends on the layer thickness ratio of the bimorph layers on the physical properties of the materials, whose range is from 0 to 1.5. Ideally the bimorph is designed to maximize it. Thus, its value is expected to be close to 1.5 according to [26].

Merging equations (2), (5), (6), and (7) the displacement of half of an half ICS bimorph is obtained as:

$$
d_{t}=\underbrace{\rho_{N I}\left(1-\cos \left(\frac{l_{N I}}{\rho_{N I}}\right)\right)}_{d_{N I}}+\underbrace{\rho_{I V}\left(1-\cos \left(\frac{l_{I V}}{\rho_{I V}}\right)\right)}_{d_{I V}}+\underbrace{L_{O L} \sin \left(\theta_{N I}\right)}_{d_{O L}}
$$

In order to obtain the total displacement of the whole bimorph it is needed to multiply equation (8) by 2. Finally considering the effect of embedded $P t$ layer, the overlap portion and the difference in the behaviours of the inverted bimorph and non-inverted bimorph explained in [24] the deflection of the entire ISC bimorph is given by equation (9) where $\mathrm{K}=0.921$. Table 1 gives parameter values of the electrothermal actuators.

$$
d_{I S C}=2 K d_{t}
$$




\section{Performance Analysis}

The aim of this section is to characterize the performance of the mirror when the piston motion is performed and thus enables an experimental validation of the model. The working voltage range goes from 0 to $3.5 \mathrm{~V}$, with a maximum power consumption of $35 \mathrm{~mW} /$ actuator.

\subsection{Experimental Setup}

The experimental setup used for the performance characterization of the MEMS mirror, includes a Keyence LC-2420 laser and a XY nanopositioning platform apart from manual positionners and an optical table. The Keyence Laser has a working range from $-250 \mu \mathrm{m}$ to $250 \mu \mathrm{m}$ with $10 \mathrm{~nm}$ resolution while the XY platform has a total displacement of $200 \mu \mathrm{m}$ for each axis. This experimental setup shown in (Fig.7) can provide single point characterization as well as planar scanning. The control of the experimental setup is performed through RT 1104 Dspace board in order to ensure a real time motion control and data acquisition. This developed experimental setup is able to perform two measurement procedures:

- Procedure 1: measurement of the relative $\mathrm{z}$ position on the center of the mirror plate in static or dynamic mode.

- Procedure 2: scanning measurement of the mirror surface during a static mode. This test consists of the scanning of a $100 \mu \mathrm{m}$ squared area of the mirror surface. While the XY platform performs 5 squares at a speed of $20 \mu \mathrm{m} / \mathrm{s}$ the Keyence laser provides a distance to the mirror for each position, obtaining at the end a cloud of points. The data obtained is processed using the PCA (Principal Component Analysis) presented in [21] which uses the maximum dispersion criterion to obtain the best fitting plane. Thus the two inclination angles of the plane are derived. 

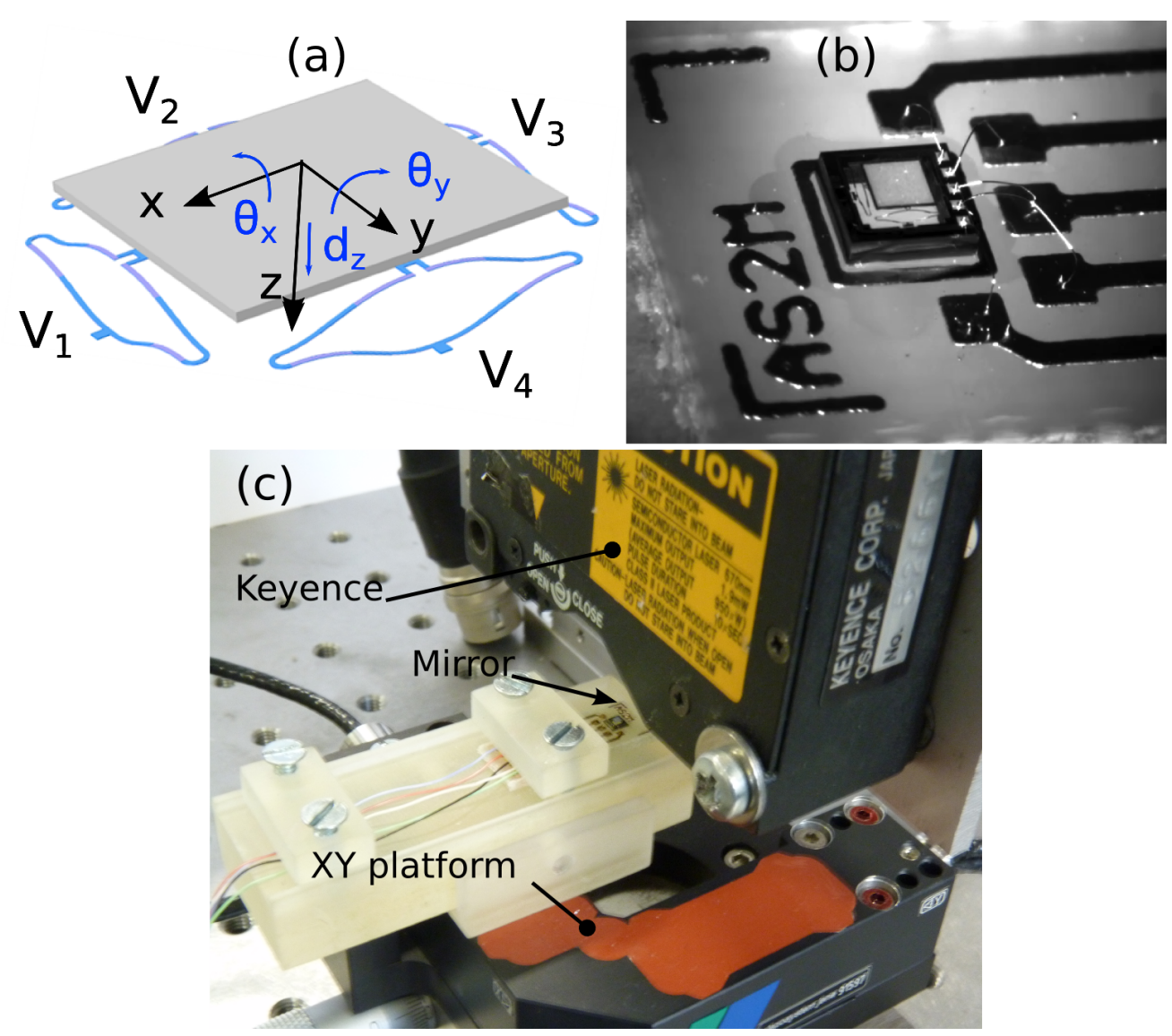

Figure 7: Experimental setup for performance characterization: (a) frame orientation, (b) mirror detail, and (c) setup description.

\subsection{Identification of $\bar{R}_{T}$}

Equivalent average thermal resistance is difficult to calculate due to the uncertainties on the obtained dimensions of each layer $\left(\mathrm{Pt}, \mathrm{Al}, \mathrm{SiO}_{2}\right)$ and the physical parameters. We propose to identify $\overline{R_{T}}$ based on measurement displacement for $3.5 \mathrm{~V}$ applied voltage and with the parameter values given in Table 1 . The calculation gives $5.7 \times 10^{3} \mathrm{~K} / \mathrm{W}$ which will be used for the model validation.

\subsection{Model validation}

The objective of this section is to validate the modeling presented before with the results obtained experimentally in static mode of procedure 1. The experimentation is performed 


\begin{tabular}{|c|c|c|}
\hline Parameter & Symbol & Value \\
\hline Non-inverted bimorph lenght & $L_{N I}$ & $250 \mu \mathrm{m}$ \\
\hline Inverted bimorph lenght & $L_{I N}$ & $125 \mu \mathrm{m}$ \\
\hline Overlap length & $L_{O L}$ & $120 \mu \mathrm{m}$ \\
\hline Bimorph total thickness & $t_{b}$ & $2.4 \mu \mathrm{m}$ \\
\hline Curvature coefficient & $\beta_{b}$ & 1.5 \\
\hline $\mathrm{Al} \mathrm{CTE}$ & $\alpha_{A l}$ & $23 \times 10^{6} K^{-1}$ \\
\hline $\mathrm{SiO}_{2} \mathrm{CTE}$ & $\alpha_{\mathrm{SiO}_{2}}$ & $0.7 \times 10^{6} K^{-1}$ \\
\hline Initial electrical resistance & $R_{0}$ & $360 \pm 15 \Omega$ \\
\hline Platinumthermal resistance coefficient & $\xi$ & $3.92 \times 10^{-3} K^{-1}$ \\
\hline CTE materials variation & $\Delta \alpha$ & $2.22 \times 10^{-5} K^{-1}$ \\
\hline Equivalent thermal coefficient of resistance & $R_{T}$ & to be identified \\
\hline
\end{tabular}

Table 1: Parameter values of the electrothermal actuators.

in the setup described before and provides the displacement amplitude of the mirror for its working voltage range.

The initial position is considered at $0 \mathrm{~V}$ where the mirror is situated around $220 \mu \mathrm{m}$ over the substrate. As steps of $0.1 \mathrm{~V}$ are applied, the mirror approaches to the substrate. Fig.8 shows the comparison between the displacement of the mirror given by the analytical model and the one provided by the experimentation.

Results show two curves with similar shape but with a slight amplitude difference between them. The experimental maximum displacement is obtained for $3.5 \mathrm{~V}$ and has a value of $173.7 \mu \mathrm{m}$. The maximum absolute error between the two curves is about $9.2 \mu \mathrm{m}$ at $1.9 \mathrm{~V}$ which corresponds to $12.4 \%$ of relative error. The difference between both can be due to several reasons, among them, fabrication tolerances, model initial assumptions as the negligibility of convection, actuator asymmetries that can introduce some torques in the joints between the actuators and the mirror plate, and some residual tangential tip tilts.

\subsection{Piston Motion Characterization}

Piston motion characterization aims to measure the behaviour of the MEMS mirror when the same DC voltage is applied to all of its actuators. For this, different experiments have been carried out, among them, dynamic step response, hysteresis measurement and static 

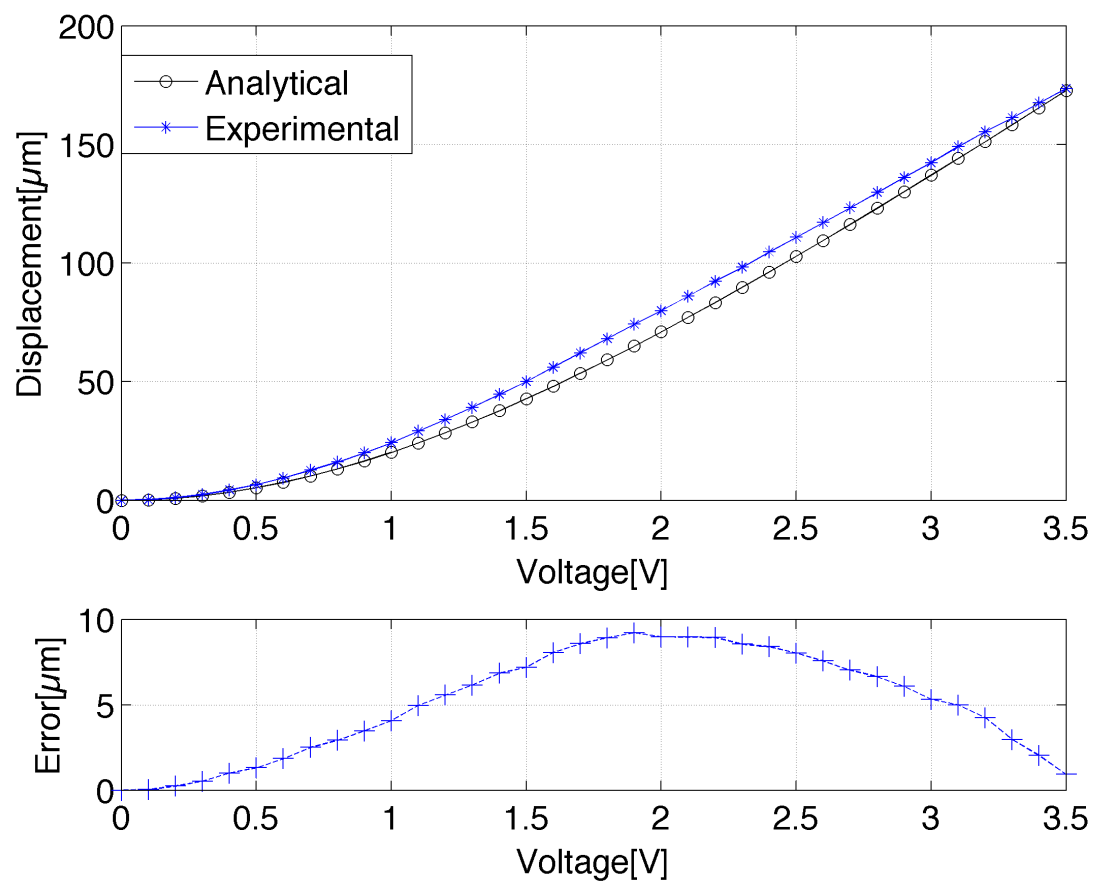

Figure 8: Absolute displacement comparison between model and experimentation and absolute error.

mirror plane scanning. They will be presented in the following.

\subsubsection{Dynamic step response}

Step response is measured through the developed experimental setup in real time. The presented results is based on one point of mirror plate measurement (procedure 1). The transient part can be observed with some oscillations for the upward (Fig.9 (b)) and downward motion (Fig.9 (c)) compared to the reference frame. A creep is observed in the static part and continued up to $30 \mathrm{~s}$, afterwards, the position is stable. The response time $t_{95 \%}$ which corresponds to the time when the measured displacement reaches $95 \%$ of its final value is measured to be $563 \mathrm{~ms}$. 


\subsubsection{Hysteresis measurement}

Hysteresis tests (procedure 1) have been done at $1 \mathrm{~V} \pm 0.5 \mathrm{~V}$ for four frequencies. Fig.10

shows that the MEMS mirror response is affected by hysteresis. The hysteresis is around $1.6 \mu \mathrm{m}$ at $0.1 \mathrm{~Hz}, 4 \mu \mathrm{m}$ at $1 \mathrm{~Hz}, 5.9 \mu \mathrm{m}$ at $20 \mathrm{~Hz}$, and $9.5 \mu \mathrm{m}$ at $100 \mathrm{~Hz}$. As the frequency of the input increases, hysteresis becomes higher and the displacement range becomes smaller.

\subsubsection{Mirror plane scanning}

With procedure 2, the experimentation provides the relative position of the mirror surface for each applied voltage. The result is presented in Fig. 11 with $3 \mathrm{D}$ representation of the mirror plate. Taking as a reference the position of the mirror when a $2 \mathrm{~V}$ offset is applied (in order to be in the middle of the entire actuation range), the two residual tilting angles are characterized.

Fig.12 shows the angle variations $\theta_{X}$ and $\theta_{Y}$ for different applied voltages. The tests has been repeated in order to prove if the variation on the tilting is changing during piston motion. The results show that the mirror plane orientation is slightly changing during the piston motion. The mean variation of $\theta_{X}$ and $\theta_{Y}$ is respectively about $0.09^{\circ}$ and $0.01^{\circ}$. In the same way the standard deviation for both angles is around $0.12^{\circ}$ or $\theta_{X}$ and $0.09^{\circ}$ for $\theta_{Y}$. This variations can be explained because of the slight differences among the electrical resistances, the thermal coefficients of the resistance, and the dimensions of the four actuators due to fabrication variations. 

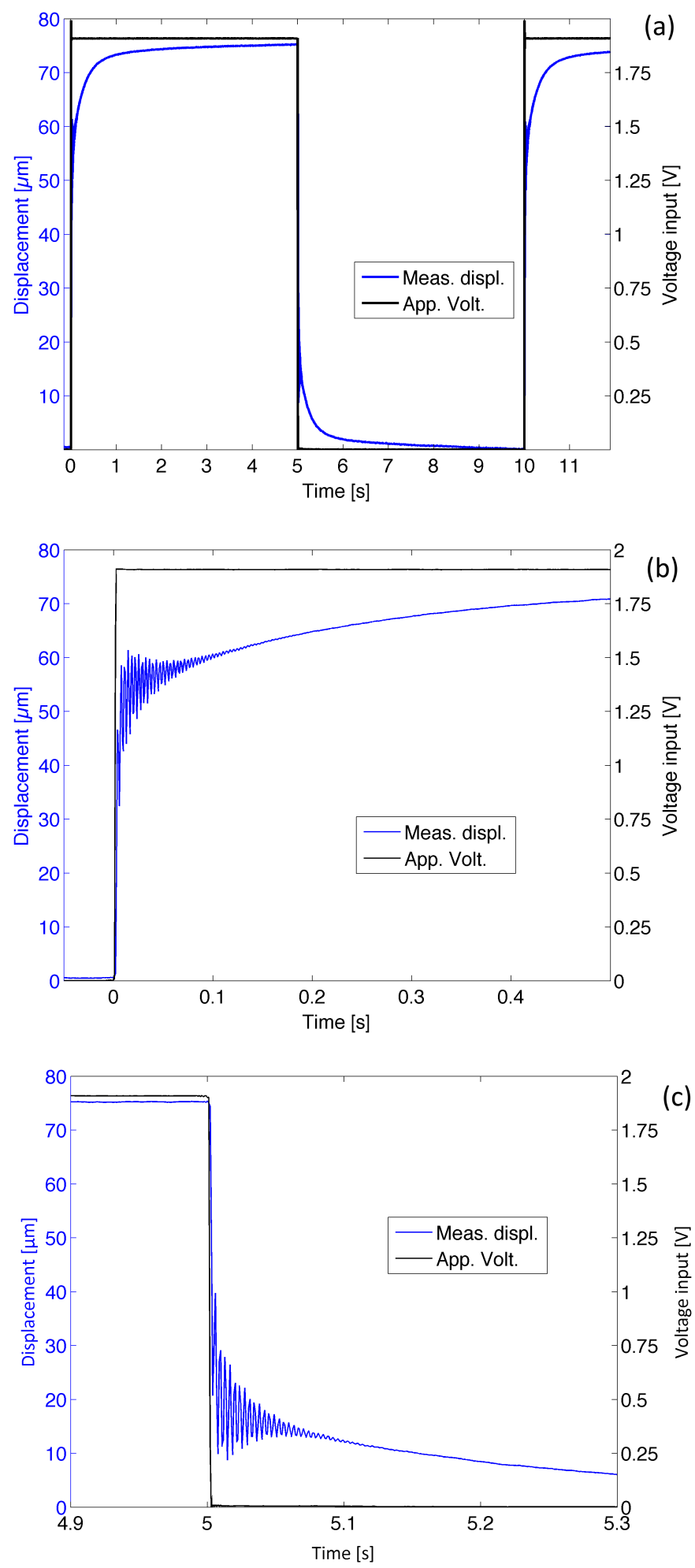

Figure 9: Step responses of the ISC actuated MEMS mirror: (a) repeating responses, (b) zoom in the upward transient part, and (c) zoom in the downward transient part compared to the reference frame. 


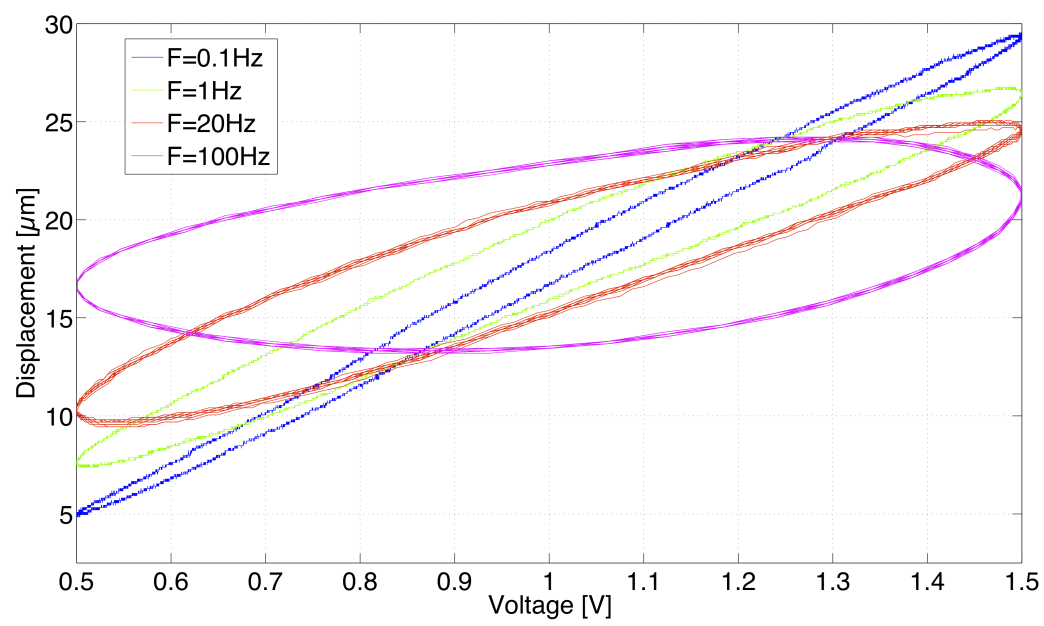

Figure 10: Hysteresis results with four frequencies of sinusoidal input voltage.

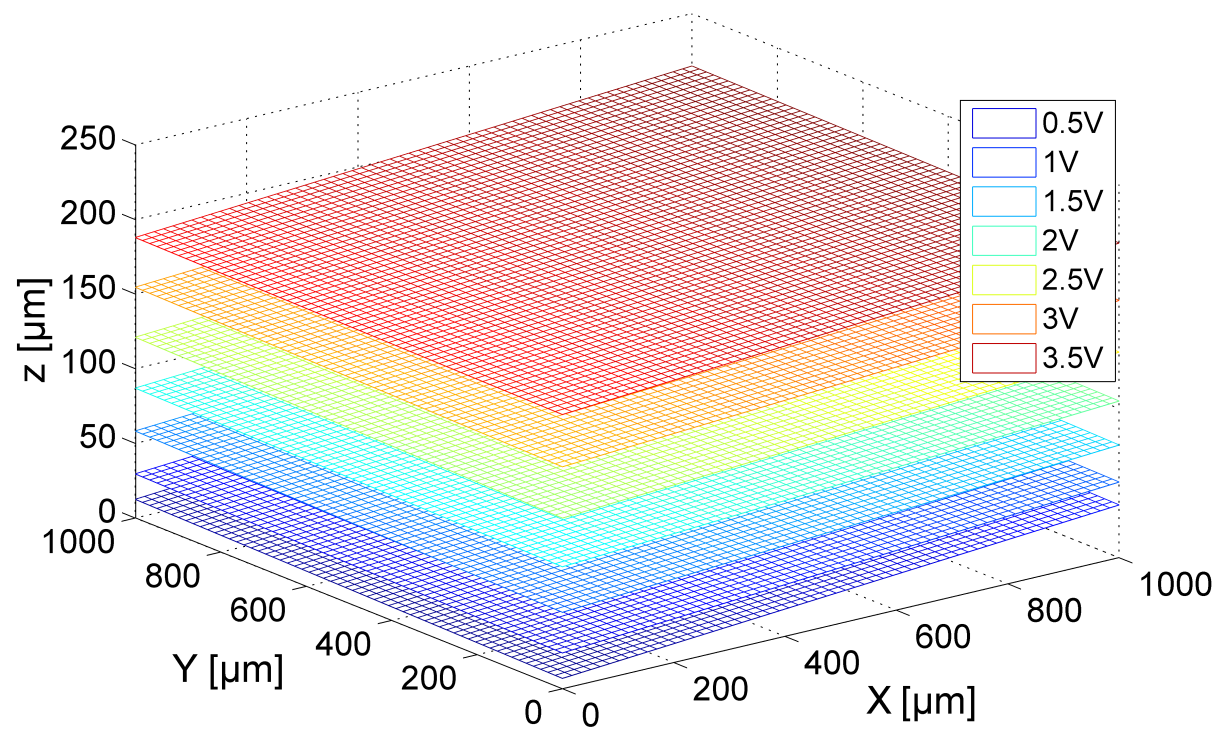

Figure 11: Mirror plane positions for different applied voltages. 
(a)

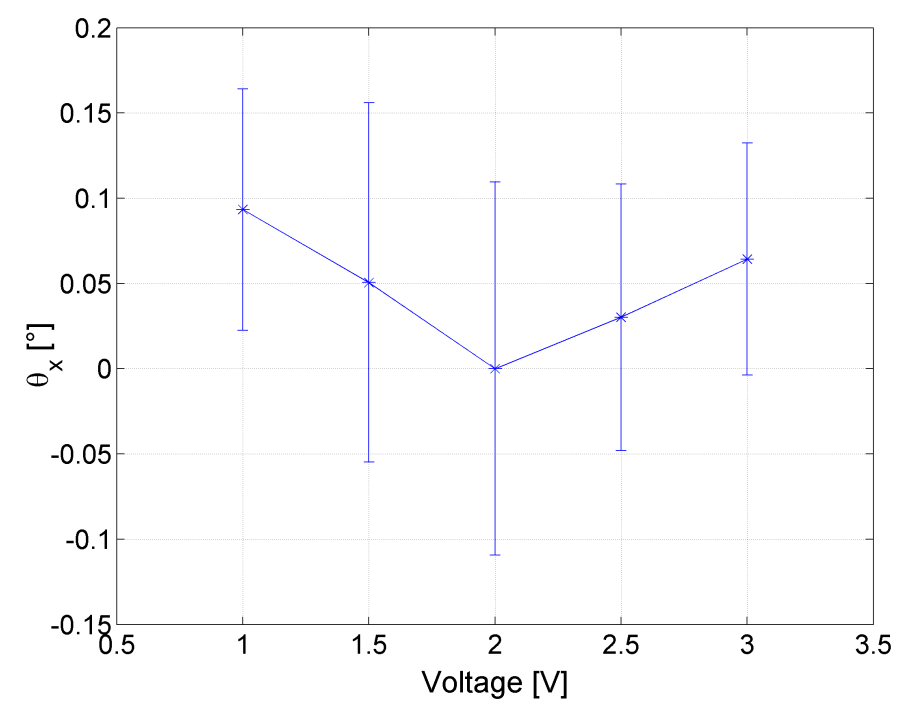

(b)

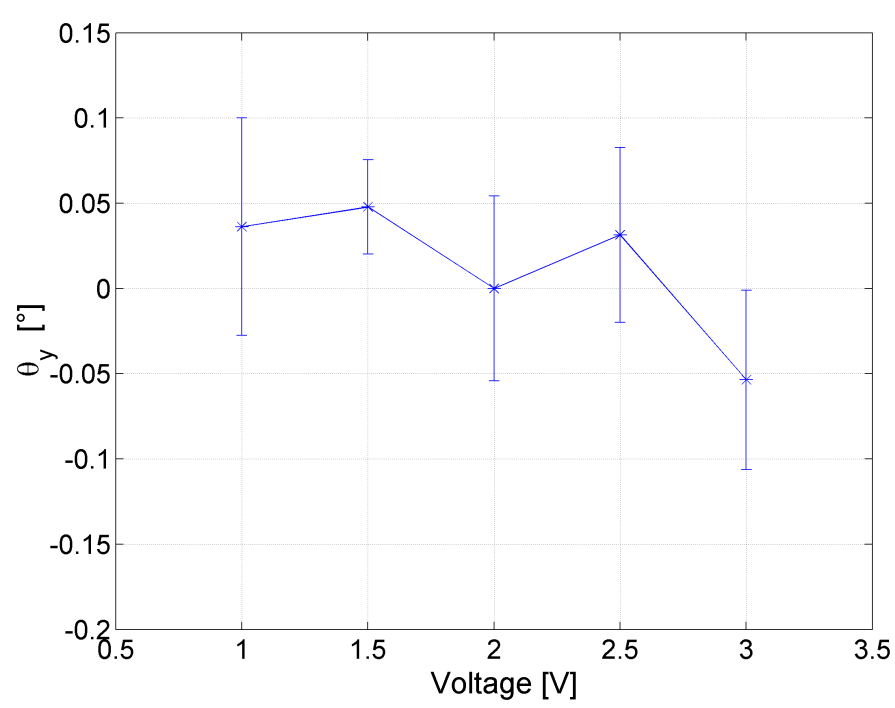

Figure 12: Angle variation for different applied voltage: (a) variation around $\mathrm{X}$ axis, and (b) variation around $\mathrm{Y}$ axis. 


\section{Conclusion}

The paper presents modeling and experimental characterization of the piston motion for a 3 DoF electrothermal MEMS mirror. It has been demonstrated a simple and effective setup experimentation able to measure motions of some hundreds of $\mu \mathrm{m}$ in size of mobile platform in both static and dynamic modes. Experimentation shows that the modeling developed fits within $9.2 \mu \mathrm{m}$ of absolute error. The piston motion is achieved within a range close to $175 \mu \mathrm{m}$ for 0 to $3.5 \mathrm{~V}$ applied voltages with some tilting variations of the mirror plate less than $0.09^{\circ}$. The step response has been characterized with a response time $t_{95 \%}$ of $563 \mathrm{~ms}$. It was observed the presence of oscillations on the transient part and creep on the static part. The hysteresis variation and the maximum displacement were observed according to frequency changes for the same applied voltage. The results are useful for understanding the MEMS mirror behaviour, for validating the design and the fabrication processes. The obtained results will enable open loop control to increase the performances and provide inputs for the future designs.Furthermore investigations in tip-tilt motion and in control domain are ongoing.

\section{Acknowledgment}

This work is partially supported by the french RENATECH and its FEMTO-ST technological facility under the Labex ACTION project (contract "ANR-11-LABX 01-01"). This is also partially supported by FP7/IRSES Net4M, Région Franche Comté by MIOP project, and the US National Science Foundation under award \#0901711.

\section{References}

[1] D. Tolfree and M. J. Jackson, editors, Commercializing Micro-Nanotechnology Products, Number 0849383153. CRC Press (2007). 
[2] Omar Manzardo, Micro-sized Fourier Spectrometers, PhD thesis EPFL (2002).

[3] U. Wallrabe, C. Solf, J. Mohr, and J. G. Korvink, "Miniaturized fourier transform spectrometer for the near infrared wavelength regime incorporating an electromagnetic linear actuator", Sensors and Actuators A 123-124, pp. 459-467 (2005).

[4] C. Gorecki, S. Bargiel, K. Laszczyk, J. Albero, J. Krezel, and M. Kujawinska, "Looking for a new generation of mems-type confocal microscopes", In 6th International Workshop on Advanced Optical Metrology. Springer (2009).

[5] J. Singh, J. H. S. Teo, Y. Xu, C. S. Premachandran, N. Chen, R. Kotlanka, M. Olivo, and C. J. R. Sheppard, "A two axes scanning soi mems micromirror for endoscopic bioimaging", Journal of Micromechanics and Microengineering 18, pp. 1-9 (2008).

[6] J. Sun and H. Xie, "Mems based endoscopic optical coherence tomography", International Journal of Optics , pp. 1-12 (2011).

[7] K. Aljasem, L. Froehly, H. Zappe, and A. Seifer, "Integrated three-dimensional scanner for endoscopic optical coherence tomography", In SPIE (2010).

[8] M. Can-Jun, Z. Fei-Ling, and Wuya-Ming, "High-speed and large-scale electromagnetically actuated resonant mems optical scanner", Chinese Physics Letters 24, pp. $3574-3577$ (2007).

[9] C. L. Hoy, W. N. Everett, M. Yildirim, J. Kobler, S. M. Zeitels, and A. Ben-Yakar, "Towards endoscopic ultrafast laser microsurgery of vocal folds", Journal of Biomedical Optics $\mathbf{1 7}(3)$ (2012).

[10] A. N. Das, J. Sin, D. O. Popa, and H. E. Stephanou, "On the precision alignment and hybrid assembly aspects in manufacturing of a microspectrometer", In IEEE Conference on Automation Science and Engineering (CASE) (2008). 
[11] Kyoungsik Yu, Daesung Lee, Uma Krishnamoorthy, Namkyoo Park, and Olav Solgaard, "Micromachined fourier transform spectrometer on silicon optical bench platform", In The 13th International Conference on Solid-State Sensors, Actuators and Microsystems. TRANSDUCERS '05 , pp. 523-530 (2005).

[12] B.A. Peterson, W.C. Patterson, F. Herrault, D.P. Arnold, and M.G. Allen, "Lasermicromachined permanent magnet arrays with spatially alternating magnetic field distribution", In PowerMEMS (2012).

[13] K. Takahashi, M. Mita, H. Fujita, and H. Toshiyoshi, "A high fill-factor comb-driven xy-stage with topological layer switch architecture", IEICE Electronics Express 3, pp. 197-202 (2006).

[14] C. Chong, K. Isamoto, and H. Toshiyoshi, "Optically modulated mems scanning endoscope", In IEEE Photonics Technology Letters (2006).

[15] A. Jain, A. Kopa, Yingtian Pan, G. K. Fedder, and H. Xie, "Two-axis electrothermal micromirror for endoscopic optical coherence tomography", IEEE Journal of Selected Topics in Quantum Electronics 10, pp. 636-642 (2004).

[16] W. Jung, J. Zhang, L. Wang, P. Wilder-Smith, Z. Chen, D. T. McCormick, and N. C. Tien, "Three-dimensional optical coherence tomography employing a 2-axis microelectromechanical scanning mirror", IEEE Journal of Selected topics in Quantum electronics 11, pp. 806-810 (2005).

[17] K. H. Kim, B. H. Park, G. N. Maguluri, T. W. Lee, F. J. Rogomentich, M. G. Bancu, B. E. Bouma, J. F. de Boer, and J. J. Bernstein, "Two-axis magnetically-driven mems scanning catheter for endoscopic high-speed optical coherence tomography", Optics express 15, pp. 18130-18140 (2007). 
[18] K. Jia, S. Pal, and H. Xie, "An electrothermal tip-tilt-piston micromirror based on folded dual s-shaped bimorphs", Journal of Microelectromechanical Systems 19, pp. 1004-1015 (2009).

[19] W. Liao, W. Liu, Y. Zhu, Y. Tang, B. Wang, and H. Xie, "A tip-tilt-piston micromirror with symmetrical lateral-shift-free piezoelectric actuators", IEEE Sensors Journal 13, pp. 2873-2881 (2013).

[20] C. Clevy, M. Rakotondrabe, and N. Chaillet, editors, Signal Measurement and Estimation Technique for Micro and Nanotechnology, Springer (2011).

[21] K. Rabenorosoa, C. Clévy, S.Bargiel, J. P. Mascaro, P. Lutz, and C. Gorecki, "Modular and reconfigurable 3d micro-optical benches : Concept, validation, and characterization", In International Manufacturing Science \& Ingineering Conference (2011).

[22] J. G. Zea, P. Sandozy andG. Laurent, L. L. Lemos, and C. Clvy, "Twin-scale vernier micro-pattern for visual measurement of 1d in-plane absolute displacements with increased range-to-resolution ratio", International Journal of Optomechatronics 7, pp. $222-234$ (2013).

[23] S. T. Todd and H. Xie, "Steady-state 1d electrothermal modeling of an electrothermal transducer", J. Micromech. Microeng. 15, pp. 2264-2276 (2005).

[24] S. T. Todd, A. Jain, H. Qu, and H. Xie, "A multi-degree-of-freedom micromirror utilizing inverted-series-connected bimorph actuators", J. Opt. A, Pure Appl. Opt. 8, pp. 352-359 (2006).

[25] W. Peng, Z. Xiao, and K. R. Famer, "Optimization of thermally actuated bimorph cantilevers for maximum deflection", In Nanotechnol. Conf. (2003). 
[26] K. Jia, S.R. Samuelson, and H. Xie, "High-fill-factor micromirror array with hidden bimorph actuators and tip-tilt-piston capability", J. Microelectromech. Syst. 20, pp. 573-582 (2011). 